\title{
Pancreatic stent eroding into the stomach
}

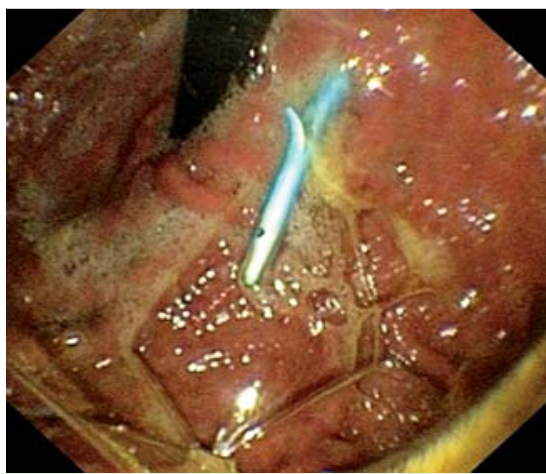

Fig. 1 One end of a stent protruding into the stomach in a 32-year-old alcoholic man with acute necrotizing pancreatitis.
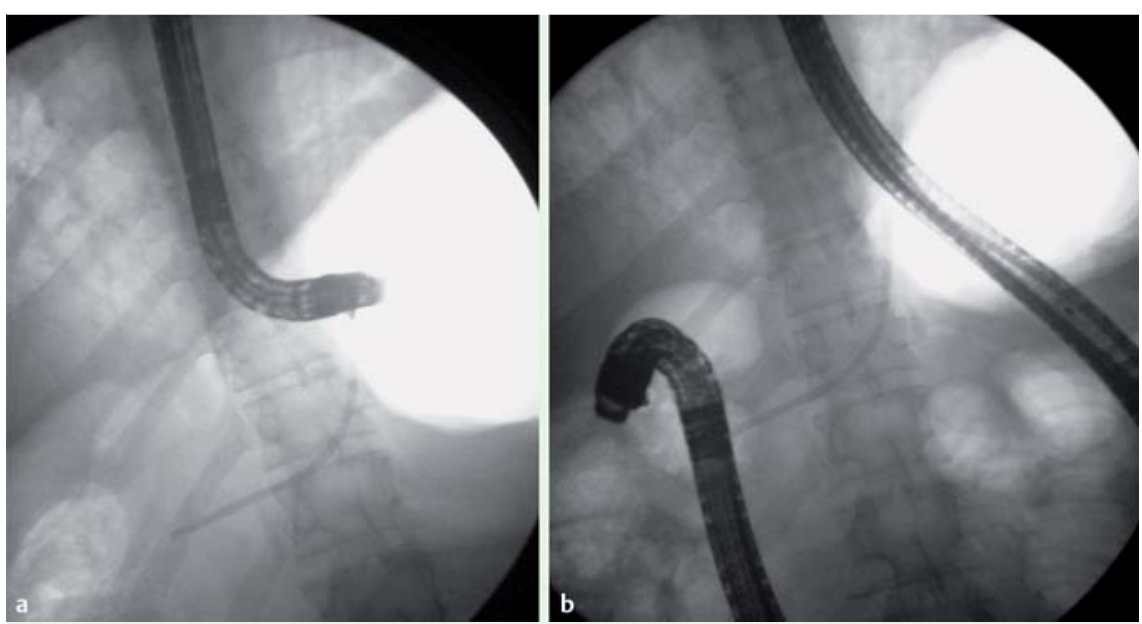

Fig. 3 a Fluoroscopic image taken with the endoscope tip close to the gastric end of the stent. b Fluoroscopic image taken with the endoscope tip close to the papillary end of the stent.

A 32-year-old alcoholic man diagnosed as having acute necrotizing pancreatitis and being managed conservatively developed high-grade fever not responsive to intravenous antibiotics. A percutaneous catheter inserted into the large, infected acute necrotic collection drained frank pus. The patient gradually improved and contrastenhanced computed tomography (CECT) 3 weeks later revealed a marked reduction in the size of the collection. The transgastric route of the percutaneous catheter was visible on the CECT scan. The catheter continued to drain $300-500 \mathrm{~mL}$ of clear pancreatic juice and 4 weeks later the patient underwent endoscopic retrograde

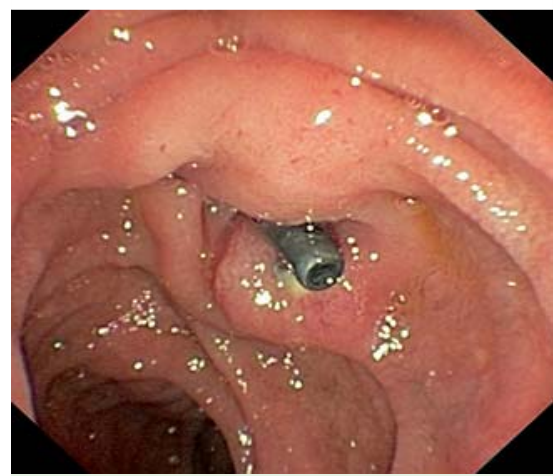

Fig. 2 The other end of the stent was at the minor papilla.

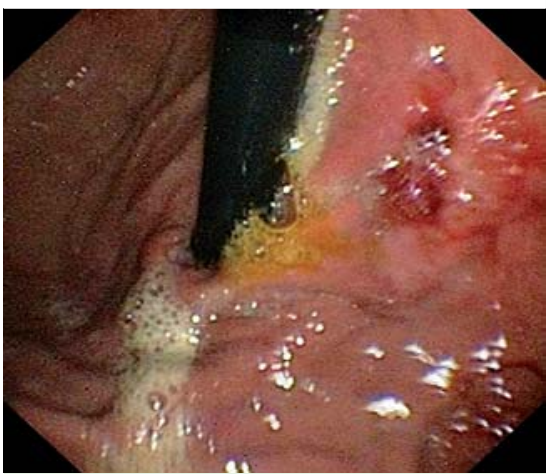

Fig. 4 Endoscopic view of the stomach following stent removal.

lary stent placed a few weeks earlier was seen at the papilla but the flanges had migrated inwards ( $\bullet$ Fig. 2). Fluoroscopic examination revealed that the transpapillary stent had migrated into the stomach through the pancreatic duct disruption, following the route created by the transgastric percutaneous catheter ( Fig.3). The stent was removed via the minor papilla ( Fig.4) and a pancreatogram revealed persistence of ductal disruption. A bridging 5-Fr transpapillary stent was placed. ERP was repeated 4 weeks later and revealed healing of both the ductal disruption and the fistulous opening in the stomach.

Transpapillary stents and nasopancreatic drains have been successfully used for healing of pancreatic ductal disruptions. Stent treatment may be associated with significant complications such as infection, stent block, duct perforation, migration, and stent-induced ductal changes [1].

Endoscopy_UCTN_Code_CPL_1AK_2AD

\section{Competing interests: None}

\section{S. S. Rana, H. S. Dhaliwal, V. Sharma, V. Chaudhary, D. K. Bhasin}

Department of Gastroenterology, Post Graduate Institute of Medical Education and Research (PGIMER), Chandigarh, India 


\section{Reference}

1 Bhasin DK, Rana SS, Nanda M et al. Comparative evaluation of transpapillary drainage with nasopancreatic drain and stent in patients with large pseudocysts located near tail of pancreas. J Gastrointest Surg 2011; 15: $772-776$

\section{Bibliography}

Dol http://dx.doi.org/

10.1055/s-0033-1344774

Endoscopy 2013; 45: E361-E362

(c) Georg Thieme Verlag KG

Stuttgart · New York

ISSN 0013-726X
Corresponding author

\section{Dr S. S. Rana}

Department of Gastroenterology Post Graduate Institute of Medical Education and Research (PGIMER)

Sector 12

Chandigarh - 160012

India

Fax: +91-172-2744401

drsurinderrana@yahoo.co.in 